\title{
A systematic, realist review of zooprophylaxis for malaria control
}

\author{
Blánaid Donnelly ${ }^{1 *}$, Lea Berrang-Ford ${ }^{1}$, Nancy A Ross ${ }^{1}$ and Pascal Michel ${ }^{2}$
}

\begin{abstract}
Background: Integrated vector management (IVM) is recommended as a sustainable approach to malaria control. IVM consists of combining vector control methods based on scientific evidence to maximize efficacy and cost-effectiveness while minimizing negative impacts, such as insecticide resistance and environmental damage. Zooprophylaxis has been identified as a possible component of IVM as livestock may draw mosquitoes away from humans, decreasing human-vector contact and malaria transmission. It is possible, however, that livestock may actually draw mosquitoes to humans, increasing malaria transmission (zoopotentiation). The goal of this paper is to take a realist approach to a systematic review of peer-reviewed literature to understand the contexts under which zooprophylaxis or zoopotentiation occur.
\end{abstract}

Methods: Three electronic databases were searched using the keywords 'zooprophylaxis' and 'zoopotentiation', and forward and backward citation tracking employed, to identify relevant articles. Only empirical, peer-reviewed articles were included. Critical appraisal was applied to articles retained for full review.

Results: Twenty empirical studies met inclusion criteria after critical appraisal. A range of experimental and observational study designs were reported. Outcome measures included human malaria infection and mosquito feeding behaviour. Two key factors were consistently associated with zooprophylaxis and zoopotentiation: the characteristics of the local mosquito vector, and the location of livestock relative to human sleeping quarters. These associations were modified by the use of bed nets and socio-economic factors.

Discussion: This review suggests that malaria risk is reduced (zooprophylaxis) in areas where predominant mosquito species do not prefer human hosts, where livestock are kept at a distance from human sleeping quarters at night, and where mosquito nets or other protective measures are used. Zoopotentiation occurs where livestock are housed within or near human sleeping quarters at night and where mosquito species prefer human hosts.

Conclusion: The evidence suggests that zooprophylaxis could be part of an effective strategy to reduce malaria transmission under specific ecological and geographical conditions. The current scientific evidence base is inconclusive on understanding the role of socio-economic factors, optimal distance between livestock and human sleeping quarters, and the effect of animal species and number on zooprophylaxis.

Keywords: Zooprophylaxis, Zoopotentiation, Malaria, Livestock, Vector-borne disease, Integrated vector management

\section{Background}

Despite renewed commitments and control efforts in recent years [1-3] malaria continues to be a major contributor to global health burden, with approximately 165

\footnotetext{
*Correspondence: blanaid.donnelly@mail.mcgill.ca

1 Department of Geography, McGill University, Burnside Hall Building, 805

Sherbrooke St West, Montreal, QC H3A 0B9, Canada

Full list of author information is available at the end of the article
}

million cases in 2013 [4]. Integrated vector management (IVM) has been promoted as a sustainable approach to combat malaria $[5,6]$ in the face of increasing insecticide resistance of malaria vectors, and environmental and health concerns [5, 7]. This strategy involves combining chemical and non-chemical interventions targeted to specific ecological settings in a way that maximizes efficacy while minimizing cost and negative 
environmental impacts [5]. IVM makes use of environmental modification, environmental manipulation, chemical control methods, and biological methods [5] (Table 1).

Strategic placement of livestock sheds or pens has also been proposed as a component of IVM to reduce contact between vectors and human hosts $[8,9]$. The World Health Organization (WHO) began recommending this type of intervention in 1982 as a method to divert mosquitoes from human populations [10]. This purposeful use of livestock (i.e. as dead-end hosts) to divert mosquitoes away from humans is described as active zooprophylaxis. Passive zooprophylaxis occurs where normal presence of livestock draws mosquitoes away from humans [11]. Insecticide zooprophylaxis, more commonly described in tsetse fly control, involves the use of insecticide-treated cattle and has also been investigated for the control of malaria vectors [12-15].

There remains considerable debate regarding the efficacy of zooprophylaxis $[10,11,16-20]$. In addition to the literature supporting zooprophylaxis [21, 22], there is evidence that supports zoopotentiation; livestock presence may actually increase malaria transmission by creating additional blood meal sources, which, in turn, can increase vector lifespan and population density $[10,11$, 16]. Due to the divergent nature of the literature and the complexity of the relationship between livestock and malaria prevalence, there has been a reluctance to employ zooprophylaxis in control programmes $[8,23,24]$.

The goal of this paper was to characterize and critically assess the potential for zooprophylaxis to reduce malaria transmission, with specific attention paid to the contexts under which it may be an effective component of IVM. The strategic framework for IVM calls for evidencebased decision-making in the selection of appropriate interventions that acknowledge the local context, including vector ecology, epidemiology and socio-economic factors [5].

\section{Methods}

A modified systematic review methodology, employing realist approaches $[25,26]$ was applied to the self-identifying zooprophylaxis literature. This approach recognizes a priori that the scientific literature in this area is conflicting and in this case focuses on when, why, and in what contexts zooprophylaxis or zoopotentiation may occur. A meta-analysis, was not feasible due to the variety of study designs (including both observational and experimental designs) and outcome measures employed in this research area. ISI Web of knowledge, CAB Direct and PubMed databases were searched in December 2014 using the keywords 'zooprophylaxis' and 'zoopotentiation. While this invariably excluded studies of malaria risk factors that consider the presence of animals, but did not self-identify using the terms 'zoopotentiation' or 'zooprophylaxis', the search was limited to these explicit terms for two reasons: (1) to select a proxy sample of the key literature explicitly emphasizing and investigating zooprophylaxis, more likely to provide direct discussion, consideration of causal pathways of association and depth regarding the role of animals in malaria transmission; and, (2) to limit the number of results to a feasible and directly relevant sample for in-depth realist analysis. This search retrieved 75 documents after removal of duplicates. Only empirical, peer-reviewed articles that focused on either malaria infection in humans or mosquito behaviour associated with livestock presence were reviewed. Mathematical models of mosquito behaviour and review articles were excluded from the synthesis but their content was assessed to provide context for interpretation of results (Table 2). A total of 20 articles met final inclusion criteria and were retained for critical appraisal after full article review (Fig. 1). Forward and backward citation tracking were applied to the articles selected for critical appraisal with one additional relevant article identified.

Data extraction from each article included author, date of publication, study location, livestock exposure, malaria risk outcome measures, study design, and study limitations. Published results reporting significant associations at the $95 \%$ confidence level were classified as supporting a significant zooprophylaxis or zoopotentiation effect. Critical appraisal [27] resulted in the exclusion of 14 articles. Reasons for exclusion (Additional file 1) were related to data analysis such as a lack of evidence of statistical significance [28, 29], and pooling of data preventing conclusions from being made on the effect of livestock on malaria risk [30]. Others were excluded based on study design issues, such as the absence of a comparison group [31] and small sample sizes [32]. The pertinent results and conclusions of each study were analysed with regard to the associations between livestock and malaria risk.

\section{Results}

\section{Study characteristics}

Twenty articles met inclusion criteria; 15 were observational studies and five were experimental (Table 3). Of the observational designs, there were 12 cross-sectional, two case-control, and one cohort design. The majority (16) of studies were conducted in sub-Saharan Africa (SSA), nine from East Africa, five from West Africa and two from Southern Africa. The remaining four studies were carried out in Pakistan (2), Bolivia (1) and Lao PDR (1). Two articles reported on a single study conducted in The Gambia, although each article reports analysis of a 





Table 2 Inclusion and exclusion criteria for document selection

\begin{tabular}{ll}
\hline Inclusion & Exclusion \\
\hline English & Non-English \\
Peer-reviewed articles presenting empirical research & $\begin{array}{l}\text { Reviews, editorials, theoretical frameworks, mathematical models, grey } \\
\text { literature, non-empirical studies }\end{array}$ \\
$\begin{array}{l}\text { Considers livestock as a predictor variable } \\
\begin{array}{l}\text { Malaria risk outcome such as human biting index or diagnosed malaria } \\
\text { infection }\end{array}\end{array}$ & No livestock variable or comparison \\
\hline
\end{tabular}

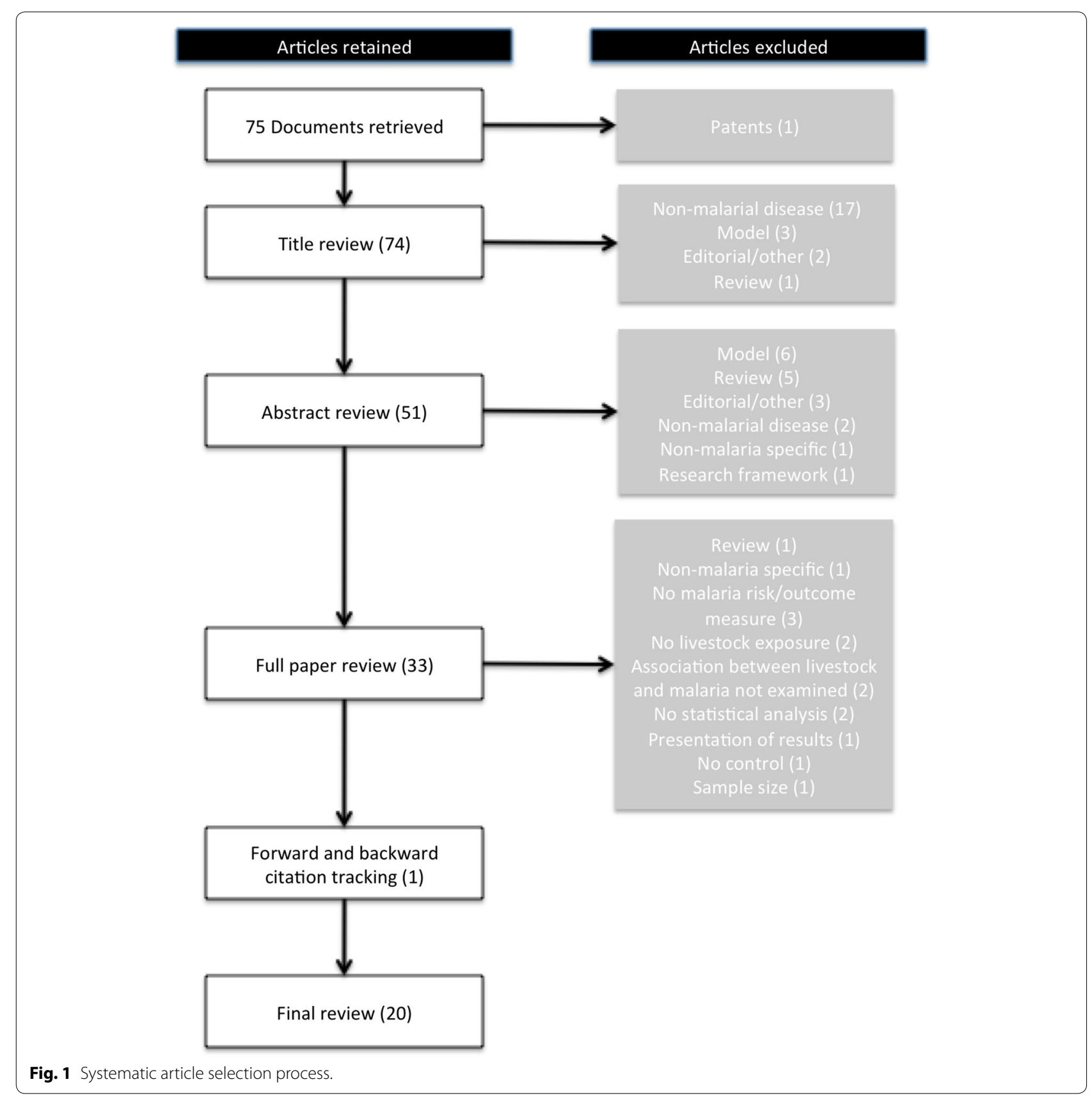




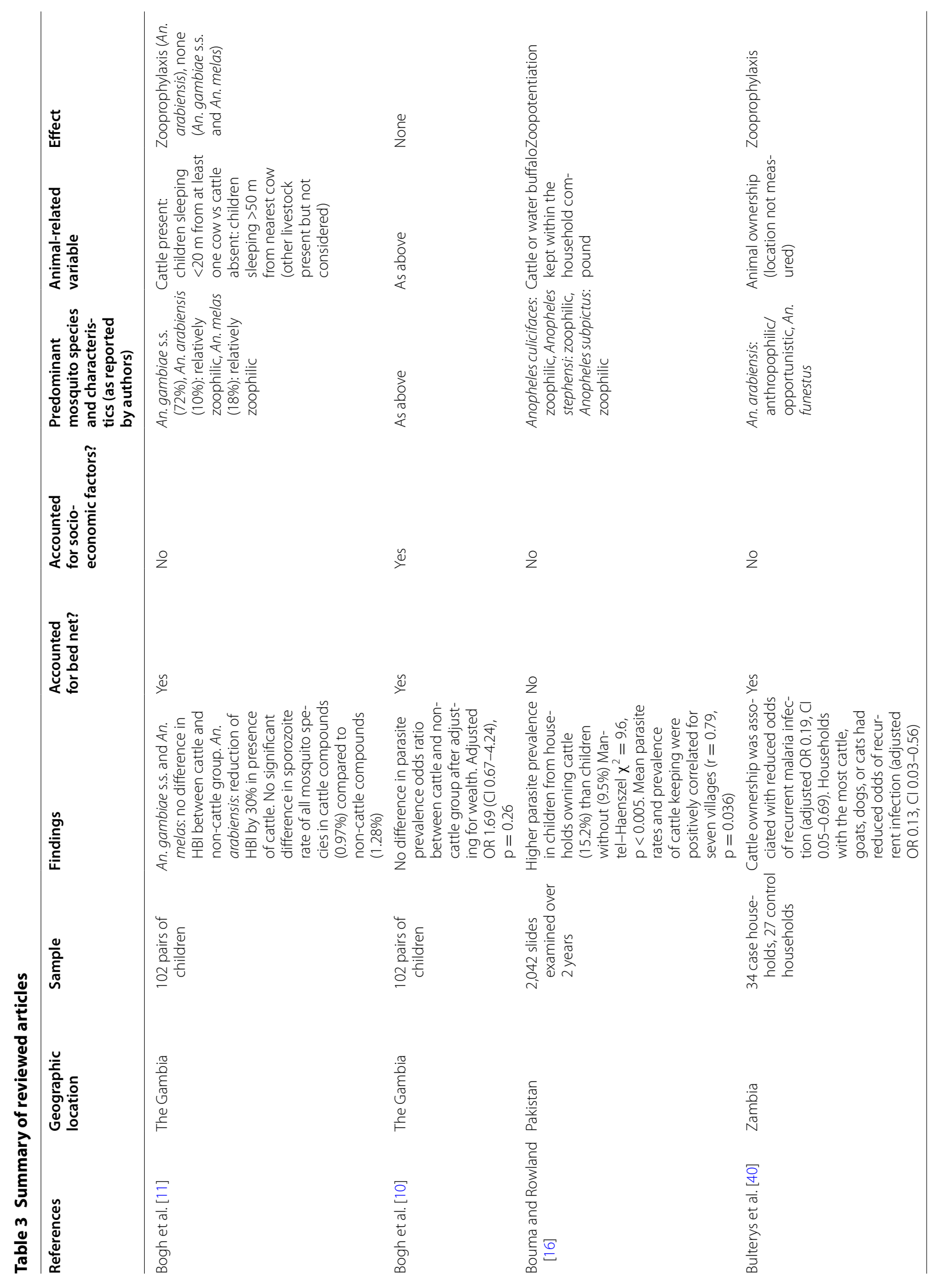




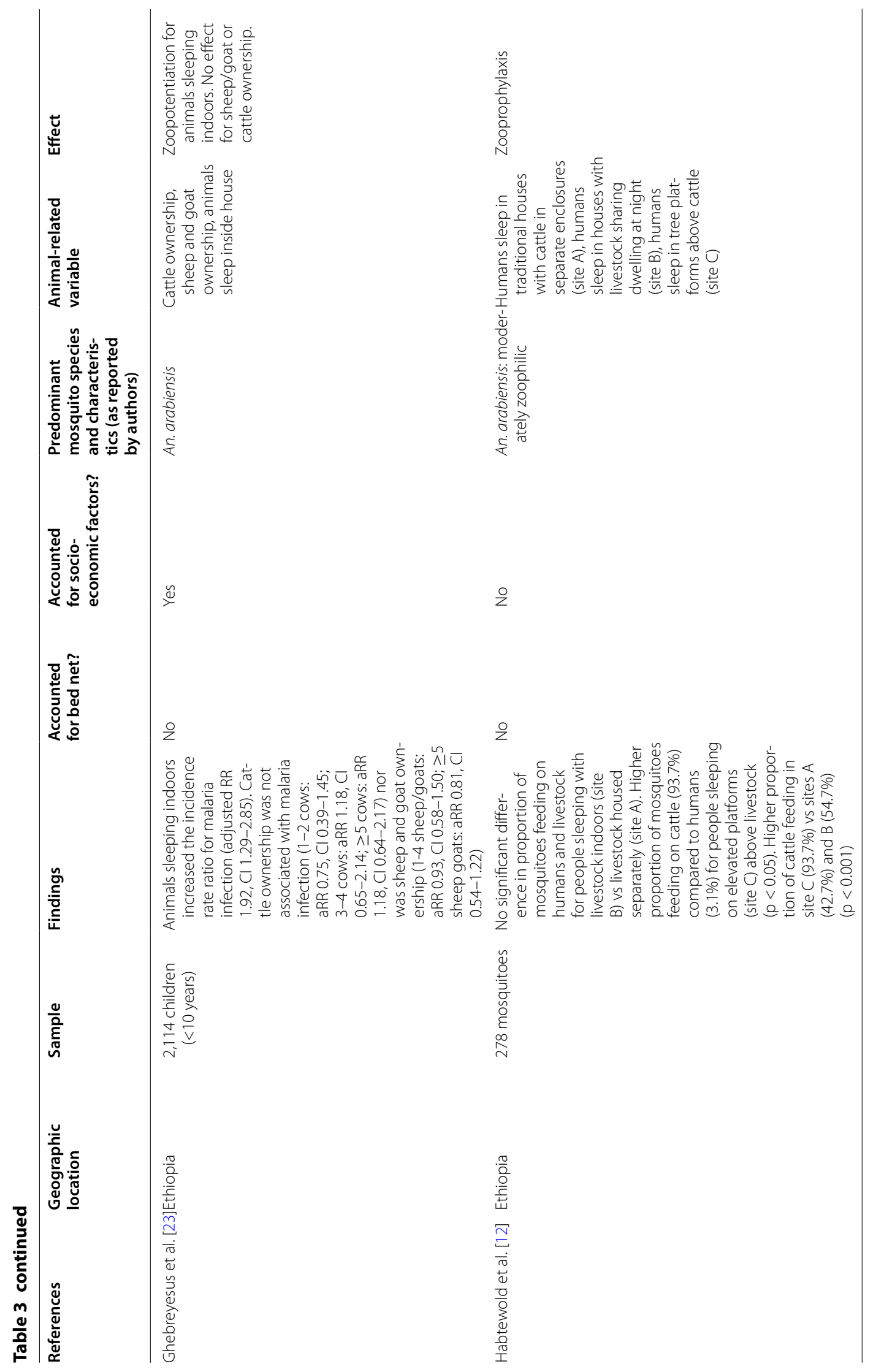




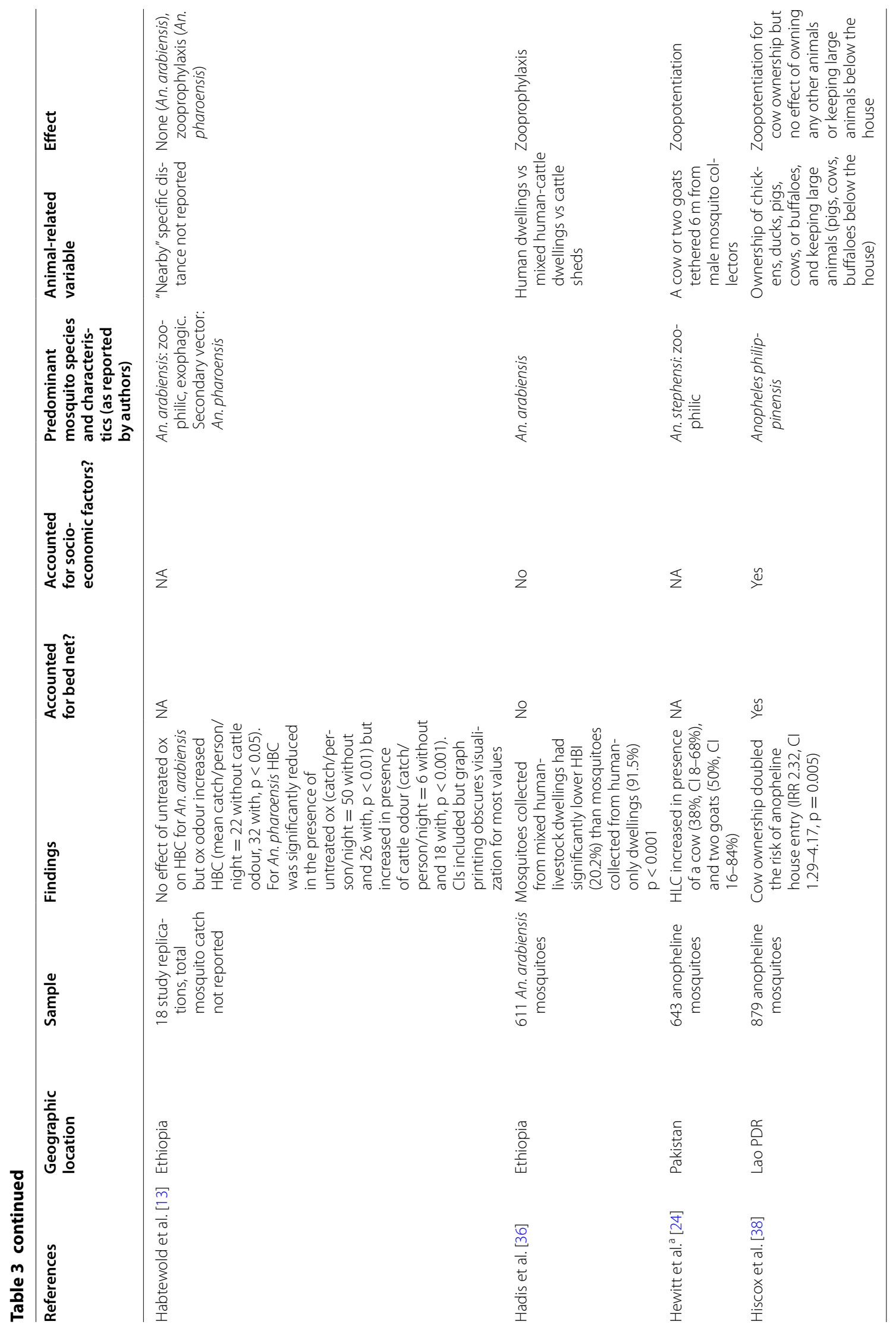




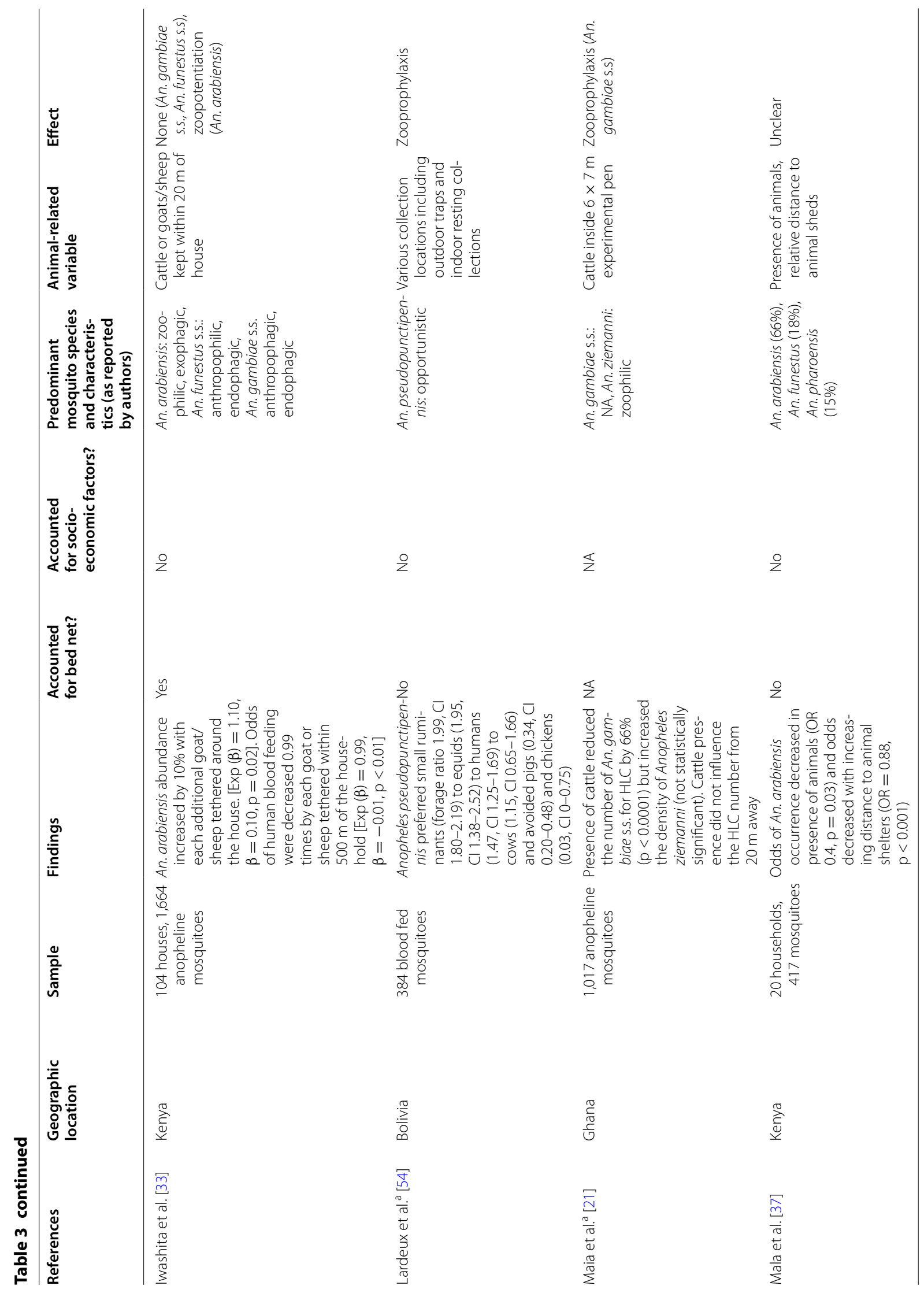









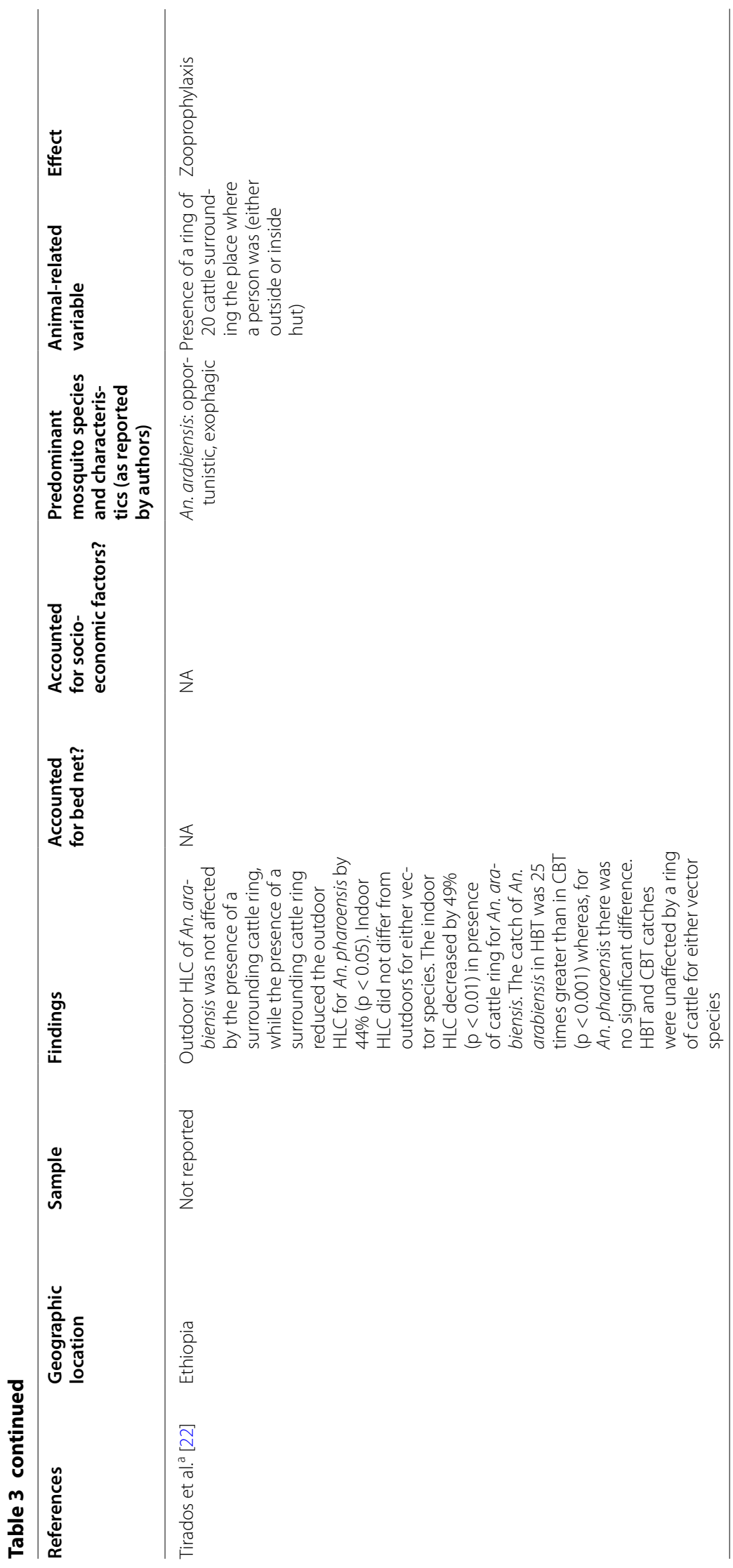




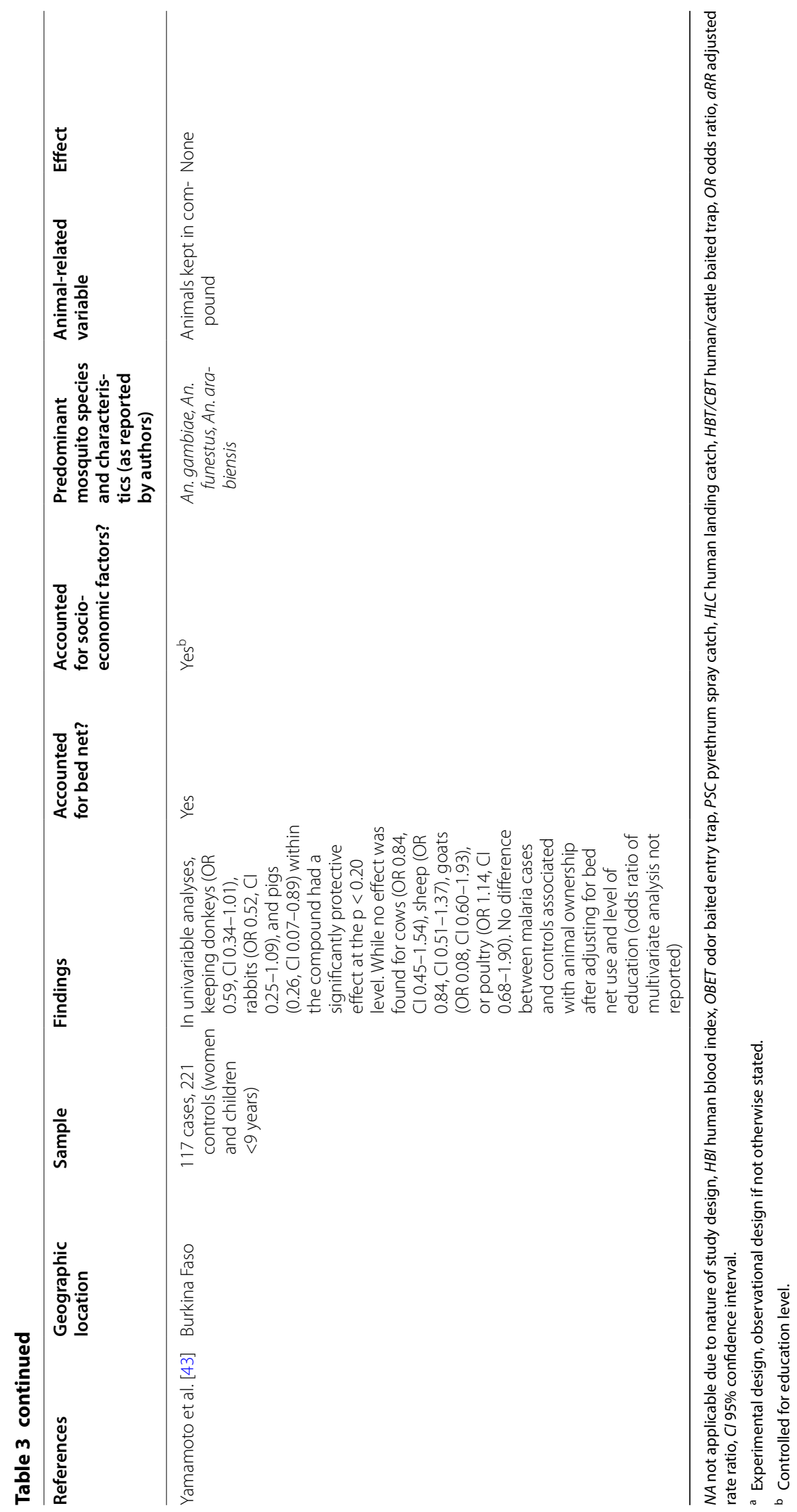


different outcome (malaria infection versus mosquito feeding behaviour).

\section{Outcome measures}

Four studies measured parasitaemia as an outcome. Three articles defined parasitaemia by positive identification of the parasite by thick and thin blood smears and one used a positive result on a malaria rapid diagnostic test (RDT). One study used recurrent household-level malaria infection defined as two or more infections for two or more household members over nine screening events but did not report the screening method used. Four studies reported mosquito feeding behaviour as measured by human blood index, which is the proportion of blood meals taken on a human out of the total number of blood meals taken. Five studies used mosquito abundance or mosquito presence as their outcome measure and four studies measured host attraction either by human landing catches or human-baited traps. One study reported both human blood index and mosquito abundance as outcome measures and another used both human blood index and host attractiveness by human landing catch.

\section{Key determinants of zooprophylaxis and zoopotentiation}

Two main factors were consistently associated with zooprophylaxis and zoopotentiation: the predominant vector species present, and the location of livestock relative to humans, particularly during peak feeding times. Zooprophylaxis was considered to be dependent on the relative preference of mosquitoes for animal hosts (zoophily) in seven studies. Where the predominant mosquito species prefers human to animal hosts (anthropophily), and human hosts are available, keeping livestock nearby is unlikely to result in zooprophylaxis. Relative zoophily was reported as an important predictor of zooprophylaxis in five studies where multiple mosquito species were present. For example, Anopheles gambiae sensu stricto and Anopheles funestus were generally found to be anthropophilic compared to other species such as Anopheles pharoensis and Anopheles arabiensis, which were readily deferred from humans to feeding on livestock species [11, 13, 22, 33].

In some cases, An. arabiensis were found to be opportunistic in their host choices, or were anthropophilic but exophagic (prefer to feed outdoors) and therefore would feed on animals if no humans were found outdoors [34]. Many of the entomological studies [11, 12, 33, 34] collected only indoor resting mosquitoes for the assessment of blood meals, which may bias samples towards endophilic (indoor resting) and endophagic (indoor feeding) species, which often tend to be anthropophilic [24]. Mosquito species were not identified in the five studies that measured human malaria infection as the outcome.

Fourteen studies found that proximity or location of livestock relative to humans influenced malaria risk. When animals were housed inside at night, or in close proximity to sleeping rooms, malaria risk increased [11, $16,23,24,33,35,36]$. In contrast, when livestock were housed in separate shelters some distance away, malaria risk decreased [22, 34, 37]. However, some studies failed to find an association between location of livestock and zooprophylaxis or zoopotentiation. For example, in Lao PDR, owning a cow doubled the risk of mosquito house entry but keeping livestock near or underneath the house at night had no effect [38]. Similarly, a cohort study in The Gambia examined parasite prevalence in children sleeping within $20 \mathrm{~m}$ of the nearest cow compared to children sleeping at least $50 \mathrm{~m}$ from the nearest cow. No difference could be found in parasite prevalence between the groups when socio-economic factors were taken into account. It should be noted, however, that other livestock, such as goats, donkeys and horses, were commonly found in participating households but were not included in the analysis [10]. While no study specifically tested the impact of keeping livestock at varying distances on malaria risk, Maia and colleagues were unable to detect an effect of cattle at a distance of $20 \mathrm{~m}$ on human landing catches of mosquitoes [21].

Relative abundance of livestock to humans, or high cattle: human ratio may influence the success of zooprophylaxis $[11,39]$. Three studies carried out in the Rift Valley of southern Ethiopia, where An. arabiensis is the main malaria vector, examined the relationship between cattle: human ratio and malaria risk. Two of these studies found no association [22, 34]. The third study did not account for the effect of humans sleeping on raised platforms in trees above cattle to avoid mosquito bites (with high cattle: human ratio) compared to the other two sites where humans slept in traditional dwellings (with lower cattle: human ratio) [12].

\section{Influence of modifying variables}

Two contextual factors were shown to modify the association between malaria risk and livestock: the use of bed nets and socio-economic status. The use of bed nets seems to be an effect modifying factor, preventing even highly anthropophilic species from feeding on humans, forcing them to feed on livestock as an alternative [33]. While two studies found that bed nets had no impact on malaria infection [40], or mosquito house entry [38] and another reported that pig ownership remained a significant risk factor for positive RDT when bed nets were accounted for [41], six studies reported a relationship between bed nets and zooprophylaxis $[8,10,11,33,42$, 
43]. In two of these studies, the effect of zooprophylaxis was diminished or became non-significant when bed net use was controlled for [10, 43]. Iwashita et al. reported that bed nets dramatically reduced human blood feeding in the presence of livestock [33]. A study conducted within a rice irrigation scheme in Kenya suggested that the cause of lower prevalence of malaria in villages where irrigation took place (and where prevalence was expected to be high) was a result of preferential feeding on livestock [8]. Bed net use was not measured in this study. Other work in the same location has suggested that bed net usage is promoted heavily in irrigated areas where malaria risk is known to be high [42].

Socio-economic status, measured as wealth or asset ownership was considered in four studies [10, 23, 38, 41]. One study identified a decrease in malaria prevalence with animal ownership, but controlling for wealth removed the effect of zooprophylaxis [10]. This study used a financial index based on livestock value to measure wealth and, therefore, collinearity might be expected between the presence of livestock and wealth. A second study noted that, in univariable analysis, sheep keeping was associated with decreased odds of infection with malaria while pig keeping was associated with increased odds of infection. When wealth was accounted for, the association with sheep ownership was no longer statistically significant while the relationship with pig ownership persisted [41]. Ghebreyesus et al. included household radio ownership in multivariable analysis and found that livestock sleeping inside the house increased incidence of infection in children [23]. Hiscox et al. did not find that household television ownership was significantly associated with mosquito house entry in univariable analysis, and it was therefore not included in multivariable analysis [38]. Yamamoto et al. controlled for maternal education level, a robust and commonly used measure of socio-economic status [44], and found that the protective effect of donkeys, rabbits and pigs was removed when level of education and bed net use were controlled for [43]. These studies and others [8] emphasized the strong association between measures of socio-economic status and malaria risk. This important association can confound the relationship between animal ownership and malaria prevalence given that animal ownership is a reflection of social standing. Socioeconomic status is likely an important unmeasured confounder affecting zooprophylaxis in the scientific evidence base.

\section{Discussion}

This systematic realist review points to three key findings regarding the context under which zooprophylaxis may be utilized as a component of IVM. First, zooprophylaxis is most likely to be effective when the mosquito species present do not have a strong preference for human hosts. Second, in order to take advantage of mosquito preference for animals, animals must be kept out of human sleeping quarters at night. There is evidence that even in the context of mosquito species with preference for animal hosts, close proximity to humans at night may result in zoopotentiation. Third, where bed nets are used, mosquitoes are more likely to feed on animal hosts as an alternative.

Proximity of livestock to humans at night has been identified as an important factor in zooprophylaxis [45]. What remains unclear is the appropriate distance at which livestock should be kept in order to promote zooprophylaxis or prevent zoopotentiation. It is also unknown whether this distance differs between regions, species and contexts. Incidence rates of Plasmodium vivax were reduced in Sri Lankan households where cattle sheds were located within $70 \mathrm{~m}$ of the home when wealth, bed nets and other protective measures were considered; however, this effect was weak (RR 0.70, 95\% CI 0.47-1.03) [46]. Current evidence supports the exclusion of animals from human dwellings at night, particularly where mosquito species are zoophilic. Improved estimation and precision around appropriate livestock proximities would benefit from the inclusion of livestock species, their number and location, and use of bed nets or other malaria prophylaxis in future studies.

Mosquito species characteristics were also identified as a key predictor of zooprophylaxis and zoopotentiation. Highly anthropophilic species were generally unaffected by the presence or absence of livestock whereas zoophilic and opportunistic species may be deterred from humans in the presence of alternative hosts. This is consistent with a model by Saul predicting that for vectors with a low human biting index, an increase in animal host density can significantly decrease disease transmission, while the same did not hold for weakly zoophilic species [18]. Similarly, Franco et al. predict that in the presence of moderately zoophilic vectors, such as An. arabiensis, the introduction of livestock would increase malaria transmission except in two cases: (1) where vector carrying capacity has already been reached in the system and the addition of livestock hosts does not increase vector density; and, (2) where livestock density and availability are so great as to counteract the effect of increased vector density associated with the introduction of livestock [47].

With regard to the impact of bed nets, since the rate of disease transmission is dependent upon host species interaction, any intervention that decreases contact between host and vector will decrease the risk of infection [5]. This has been corroborated by mathematical transmission models which find that while increased 
cattle density can decrease malaria transmission when sufficient animals are present and are housed separately, the most successful reduction transmission occurs when personal protective measures are also employed [18, 39]. Where accessibility of humans relative to animals is decreased, it is predicted that malaria prevalence and number of bites will decrease [18, 47]. Time of biting and human behaviour may also have an impact on the effectiveness of bed nets. If people are outdoors during peak biting times, bed nets will not provide protection against mosquito bites [21].

Socio-economic factors may be important unmeasured confounders in studies of zooprophylaxis. Risk factors for malaria are related to poverty through limited access to preventative measures such as bed nets, screened windows, closed roofing, and adequate health care [48]. Livestock ownership is also associated with increased socio-economic status, especially among the rural poor [49-51]. It has been suggested that in addition to zooprophylactic effects, livestock may be a confounder for reduced malaria risk as those who own livestock may also be able to afford preventative and treatment measures [10] or have better overall health and nutritional status $[51,52]$. Households keeping animals indoors at night may represent those who are financially restricted from providing alternative livestock shelters, further complicating the inter-relationships between wealth and animal ownership in malaria transmission.

\section{Conclusions}

There is scientific evidence to support zooprophylaxis where the dominant vector is highly zoophilic and livestock are kept away from human sleeping quarters during peak vector activity. The use of protection such as bed nets may be complementary, and would be expected to reduce the measured effect of zooprophylaxis in empirical studies. Where vector preference is mixed, varied or unknown, or where the appropriate distance of livestock from sleeping quarters is in debate, there is insufficient evidence to support the use of zooprophylaxis, and some evidence to suggest the possibility of zoopotentiation. Research in three priority areas is required for clearer evidence of contexts to maximize the likelihood of zooprophylaxis and minimize the likelihood of zoopotentiation: (1) estimation of the distance threshold and conditions whereby processes of zoopotentiation transition to zooprophylaxis for specific livestock host and mosquito vector species combinations; (2) consideration of the preference of species to feed indoors versus outdoors in entomologic studies in order to accurately assess mosquito host preferences; and, (3) inclusion of socio-economic factors and the use of other prophylactic measures as key covariates in empirical research assessing zooprophylaxis and zoopotentiation. These research priorities may aid in the development of guidelines for the use of zooprophylaxis as a malaria control intervention for agricultural extension agencies who may wish to make livestock management recommendations, such as the optimal placement of livestock shelters with respect to human sleeping quarters. Zooprophylaxis has the potential to contribute to IVM strategies due to its non-chemical nature, optimal combination with bed nets, potential social desirability, and minimal financial requirements. It will require interdisciplinary collaboration between agricultural extension officers, veterinarians and health care professionals with ongoing monitoring of efficacy.

\section{Additional file}

Additional file 1: Articles excluded from review and reasons for exclusion

\section{Authors' contributions}

$\mathrm{BD}, \mathrm{PM}$ and LBF conceptualized the research question. BD carried out the data collection and analysis. LBF contributed to the interpretation of results while $\mathrm{BD}$ and NR drafted the discussion. All authors engaged in critical revisions of the manuscript. All authors read and approved the final manuscript.

\section{Author details}

${ }^{1}$ Department of Geography, McGill University, Burnside Hall Building, 805 Sherbrooke St West, Montreal, QC H3A OB9, Canada. ${ }^{2}$ Public Health Risk Sciences Division, Public Health Agency of Canada, 3200 Sicotte, PO Box 5000, Saint-Hyacinthe, QC J2S 7C6, Canada.

\section{Acknowledgements}

This work was partly funded by the Public Health Risk Sciences Division of the Public Health Agency of Canada. BD would like to acknowledge funding from the Indigenous Health Adaptation to Health (IHACC) project. BD would also like to thank Lorna Sampson for feedback on an earlier version of this manuscript. We would like to acknowledge the anonymous reviewer for their detailed and constructive comments.

Compliance with ethical guidelines

\section{Competing interests}

The authors declare that they have no competing interests.

Received: 4 February 2015 Accepted: 28 July 2015

Published online: 12 August 2015

\section{References}

1. Eisele TP, Larsen DA, Walker N, Cibulskis RE, Yukich JO, Zikusooka CM et al (2012) Estimates of child deaths prevented from malaria prevention scale-up in Africa 2001-2010. Malar J 11:93

2. Siri JG (2014) Independent associations of maternal education and household wealth with malaria risk in children. Ecol Soc 19:33

3. Cox J, Hay SI, Abeku TA, Checchi F, Snow RW (2007) The uncertain burden of Plasmodium falciparum epidemics in Africa. Trends Parasitol 23:142-148

4. Murray CJL, Ortblad KF, Guinovart C, Lim SS, Wolock TM, Roberts DA et al (2014) Global, regional, and national incidence and mortality for HIV, tuberculosis, and malaria during 1990-2013: a systematic analysis for the Global Burden of Disease Study 2013. Lancet 384:1005-1070 
5. World Health Organization (2004) Global Strategic Framework for Integrated Vector Management. http://www.who.int/malaria/publications/ atoz/who_cds_cpe_pvc_2004_10/en/. Accessed 5 Aug 2014

6. Mutero CM, Schlodder D, Kabatereine N, Kramer R (2012) Integrated vector management for malaria control in Uganda: knowledge, perceptions and policy development. Malar J 11:21

7. World Health Organization (2001) Action Plan for the Reduction of Reliance on DDT in Disease Vector Control. http://whqlibdoc.who.int/ hq/2001/WHO_SDE_WSH_01.5.pdf. Accessed 5 Aug 2015

8. Mutero CM, Kabutha C, Kimani V, Kabuage L, Gitau G, Ssennyonga J et al (2004) A transdisciplinary perspective on the links between malaria and agroecosystems in Kenya. Acta Trop 89:171-186

9. Walker K (2002) A review of control methods for African malaria vectors. Environmental Health Project. http://www.ehproject.org/PDF/Activity_Reports/AR108MalRevArch.pdf. Accessed 5 Aug 2014

10. Bogh C, Clarke SE, Walraven GEL, Lindsay SW (2002) Zooprophylaxis, artefact or reality? A paired-cohort study of the effect of passive zooprophylaxis on malaria in The Gambia. Trans R Soc Trop Med Hyg 96:593-596

11. Bogh C, Clarke SE, Pinder M, Sanyang F, Lindsay SW (2001) Effect of passive zooprophylaxis on malaria transmission in the Gambia. J Med Entomol 38:822-828

12. Habtewold T, Walker AR, Curtis CF, Osir EO, Thapa N (2001) The feeding behaviour and Plasmodium infection of Anopheles mosquitoes in southern Ethiopia in relation to use of insecticide-treated livestock for malaria control. Trans R Soc Trop Med Hyg 95:584-586

13. Habtewold T, Prior A, Torr SJ, Gibson G (2004) Could insecticide-treated cattle reduce Afrotropical malaria transmission? Effects of deltamethrintreated Zebu on Anopheles arabiensis behaviour and survival in Ethiopia. Med Vet Entomol 18:408-417

14. Mahande AM, Mosha FW, Mahande JM, Kweka EJ (2007) Role of cattle treated with deltamethrine in areas with a high population of Anopheles arabiensis in Moshi, Northern Tanzania. Malar J 6:109

15. Rowland M, Durrani N, Kenward M, Mohammed N, Urahman H, Hewitt S (2001) Control of malaria in Pakistan by applying deltamethrin insecticide to cattle: a community-randomised trial. Lancet 357:1837-1841

16. Bouma M, Rowland M (1995) Failure of passive zooprophylaxis_cattle ownership in Pakistan is associated with a higher prevalence of malaria. Trans R Soc Trop Med Hyg 89:351-353

17. Charlwood D (2001) Zooprophylaxis: are we in Plato's cave? Trends Parasitol 17:517

18. Saul A (2003) Zooprophylaxis or zoopotentiation: the outcome of introducing animals on vector transmission is highly dependent on the mosquito mortality while searching. Malar J 2:32

19. Bhutta ZA, Ahmed T, Black RE, Cousens S, Dewey K, Giugliani E et al (2008) What works? Interventions for maternal and child undernutrition and survival. Lancet 371:417-440

20. World Health Organization (1982) Manual on environmental management for mosquito control. WHO Offset publication No.66. 1982. http:// whqlibdoc.who.int/publications/1982/9241700661_eng.pdf. Accessed 5 Aug 2014

21. Maia MF, Abonuusum A, Lorenz LM, Clausen P-H, Bauer B, Garms R et al (2012) The effect of deltamethrin-treated net fencing around cattle enclosures on outdoor-biting mosquitoes in Kumasi, Ghana. PLoS One 7:e45794

22. Tirados I, Gibson G, Young S, Torr SJ (2011) Are herders protected by their herds? An experimental analysis of zooprophylaxis against the malaria vector Anopheles arabiensis. Malar J 10:68

23. Ghebreyesus TA, Haile M, Witten KH, Getachew A, Yohannes M, Lindsay SW et al (2000) Household risk factors for malaria among children in the Ethiopian highlands. Trans R Soc Trop Med Hyg 94:17-21

24. Hewitt S, Kamal M, Muhammad N, Rowland M (1994) An entomological investigation of the likely impact of cattle ownership on malaria in an Afghan refugee camp in the North-West Frontier Province of Pakistan. Med Vet Entomol 8:160-164

25. Pawson R, Greenhalgh T, Harvey G, Walshe K (2004) Realist synthesis: an introduction. In: ESRC Research Methods Programme Working Paper Series, vol 2. http://betterevaluation.org/sites/default/files/RMPmethods2.pdf. Accessed 3 April 2013

26. Pawson R, Greenhalgh T, Harvey G, Walshe K (2005) Realist review - a new method of systematic review designed for complex policy interventions. J Health Serv Res Policy 10(Suppl 1):21-34
27. Heller RF, Verma A, GemmeH I, Harrison R, Hart J, Edwards R (2008) Critical appraisal for public health: a new checklist. Public Health 122:92-98

28. Supalin SK (1986) Zooprophylaxis as a useful tool for control of $A$. aconitus transmitted malaria in Central Java, Indonesia. J Commun Dis 18:90-94

29. Mahande A, Mosha F, Mahande J, Kweka E (2007) Feeding and resting behaviour of malaria vector, Anopheles arabiensis with reference to zooprophylaxis. Malar J 6:100

30. Kaburi JC, Githuto JN, Muthami L, Ngure PK, Mueke JM, Mwandawiro CS (2009) Effects of long-lasting insecticidal nets and zooprophylaxis on mosquito feeding behaviour and density in Mwea, central Kenya. J Vector Borne Dis 46:184-190

31. Bhatt RM, Srivastava HC, Yadav RS (2008) Dynamics of Anopheles culicifacies-transmitted malaria in the absence of effective zooprophylaxis in a riverine settlement in Gujarat, India. Curr Sci 95:82-87

32. McCall PJ, Mosha FW, Njunwa KJ, Sherlock K (2001) Evidence for memorized site-fidelity in Anopheles arabiensis. Trans R Soc Trop Med Hyg 95:587-590

33. Iwashita H, Dida GO, Sonye GO, Sunahara T, Futami K, Njenga SM et al (2014) Push by a net, pull by a cow: can zooprophylaxis enhance the impact of insecticide treated bed nets on malaria control? Parasit Vectors 7:15

34. Tirados I, Costantini C, Gibson G, Torr SJ (2006) Blood-feeding behaviour of the malarial mosquito Anopheles arabiensis: implications for vector control. Med Vet Entomol 20:425-437

35. Palsson K, Jaenson TGT, Dias F, Laugen AT, Bjorkman A (2004) Endophilic Anopheles mosquitoes in Guinea Bissau, West Africa, in relation to human housing conditions. J Med Entomol 41:746-752

36. Hadis M, Lulu M, Makonnen Y, Asfaw T (1997) Host choice by indoorresting Anopheles arabiensis in Ethiopia. Trans R Soc Trop Med Hyg 91:376-378

37. Mala AO, Irungu LW, Shililu JI, Muturi EJ, Mbogo CM, Njagi JK et al (2011) Plasmodium falciparum transmission and aridity: a Kenyan experience from the dry lands of Baringo and its implications for Anopheles arabiensis control. Malar J 10:121

38. Hiscox A, Khammanithong P, Kaul S, Sananikhom P, Luthi R, Hill N et al (2013) Risk factors for mosquito house entry in the Lao PDR. PLoS One $8: 10$

39. Sota T, Mogi M (1989) Effectiveness of zooprophylaxis in malaria control-a theoretical inquiry, with a model for mosquito populations with 2 bloodmeal hosts. Med Vet Entomol 3:337-345

40. Bulterys PL, Mharakurwa S, Thuma PE (2009) Cattle, other domestic animal ownership, and distance between dwelling structures are associated with reduced risk of recurrent Plasmodium falciparum infection in southern Zambia. Trop Med Int Health 14:522-528

41. Temu EA, Coleman M, Abilio AP, Kleinschmidt I (2012) High prevalence of malaria in Zambezia, Mozambique: the protective effect of IRS versus increased risks due to pig-keeping and house construction. PLoS One 7:e31409

42. Muriu SM, Muturi EJ, Shililu J, Mbogo CM, Mwangangi JM, Jacob BG et al (2008) Host choice and multiple blood feeding behaviour of malaria vectors and other anophelines in Mwea rice scheme, Kenya. Malar J 7:43

43. Yamamoto SS, Louis VR, Sie A, Sauerborn R (2009) The effects of zooprophylaxis and other mosquito control measures against malaria in Nouna, Burkina Faso. Malar J 8:283

44. Bollen KA, Glanville JL, Stecklov G (2001) Socioeconomic status and class in studies of fertility and health in developing countries. Annu Rev Sociol 27:153-185

45. Hassanali A, Nedorezov LV, Sadykou AM (2008) Zooprophylactic diversion of mosquitoes from human to alternative hosts: a static simulation model. Ecol Model 212:155-161

46. van der Hoek W, Konradsen F, Dijkstra DS, Amerasinghe PH, Amerasinghe FP (1998) Risk factors for malaria: a microepidemiological study in a village in Sri Lanka. Trans R Soc Trop Med Hyg 92:265-269

47. Franco AO, Gomes MGM, Rowland M, Coleman PG, Davies CR (2014) Controlling malaria using livestock-based interventions: a one health approach. PLoS One 9:e101699

48. Worrall E, Basu S, Hanson K (2005) Is malaria a disease of poverty? A review of the literature. Trop Med Int Health 10:1047-1059 
49. Kitalyi A, Mtenga L, Morton J, McLeod A, Thornton P, Dorward A et al (2005) Why keep livestock if you are poor? In: Owen EA, Kitalyi A, Jayasuriya N, Amith T (eds) Livestock and wealth creation: improving the husbandry of animals kept by resource-poor people in developing Countries. Nottingham University Press, Nottingham, pp 13-27

50. Upton M (2004) The Role of Livestock in Economic Development and Poverty Reduction. Pro-Poor Livestock Policy Initiative Working Papers, vol 10. Food and Agriculture Organization. http://www.fao.org/ag/againfo/ programmes/en/pplpi/docarc/wp10.pdf. Accessed 1 May 2013

51. Randolph TF, Schelling E, Grace D, Nicholson CF, Leroy JL, Cole DC et al (2007) Role of livestock in human nutrition and health for poverty reduction in developing countries. J Anim Sci 85:2788-2800
52. Girard AW, Self JL, McAuliffe C, Olude O (2012) The effects of household food production strategies on the health and nutrition outcomes of women and young children: a systematic review. Paediatr Perinat Epidemiol 26(Suppl 1):205-222

53. World Health Organization (1980) Environmental management for vector control. Fourth report of the WHO Expert Committee on Vector Biology and Control. http://apps.who.int/iris/bitstream/10665/41404/1/WHO_ TRS_649.pdf?ua=1. Accessed 19 Nov 2014

54. Lardeux F, Loayza P, Bouchite B, Chavez T (2007) Host choice and human blood index of Anopheles pseudopunctipennis in a village of the Andean valleys of Bolivia. Malar J 6:8
Submit your next manuscript to BioMed Central and take full advantage of:

- Convenient online submission

- Thorough peer review

- No space constraints or color figure charges

- Immediate publication on acceptance

- Inclusion in PubMed, CAS, Scopus and Google Scholar

- Research which is freely available for redistribution

Submit your manuscript at

www.biomedcentral.com/submit 